\title{
A Systematic Review of Sustainable Supply Chain Management Practices in Food Industry
}

\author{
Federica Minardi ${ }^{1}$, Valérie Botta-Genoulaz ${ }^{1}$ and Giulio Mangano ${ }^{2}$ \\ ${ }^{1}$ Univ Lyon, INSA Lyon, Université Claude Bernard Lyon 1, Univ Lumière Lyon 2, DISP, \\ EA4570, 69621 Villeurbanne, France \\ ${ }^{2}$ Department of Management and Production Engineering, Politecnico di Torino, 10129 Turin, \\ Italy \\ federica.minardilinsa-lyon.fr, valerie.bottalinsa-lyon.fr, \\ giulio.manganoepolito.it
}

\begin{abstract}
The food industry is central to human beings and heavily impacts the lives of the entire society. Nowadays, the sustainable development goal and the introduction of new information and communication technologies has led food companies to deal with this new paradigm. They require sustainable practices that have the dual objective of improving the overall performance of the company itself and fulfilling the sustainability requirement. Research works on sustainable supply chain management practices in the food industry is quite fragmented, as it often considers just a part of the chain. Therefore, through a systematic literature review, this paper aims to provide an up-to-date analysis of supply chain management practices within the scope of sustainability, studying the findings of 224 reviewed papers. The implications of this work are relevant for academic research as they enlarge the body of knowledge and highlight key points where there is the need to investigate further. From a practical point of view this study proposes an overview of the most common and adopted practices that can be implemented in order to achieve sustainable development in the food industry.
\end{abstract}

Keywords: Systematic Literature Review, Supply Chain Management, Sustainable development, Food Industry.

\section{Introduction}

Food Supply Chain (FSC) refers to the set of processes that describe how food from a farm ends up on the table. Several dimensions are particularly critical in a FSC namely quality, safety, sustainability, and logistic efficiency (Rohmer, Gerdessen, \& Claassen, 2019), (Manzini \& Accorsi, 2012). Moreover, "internationalization, along with the need to keep up with sustainable development goals, has increased the level of global competition among companies, with conventional business models struggling to find adequate solutions" (Nosratabadi, et al., 2019). In order to achieve a competitive advantage in the market, firms are called to integrate the concept of sustainability in their supply chain operations (Rehman Khan, Yu, Golpira, Sharif, \& Mardani, 2021). Sustainability or Sustainable Development (SD) is defined as "the development that meets 
$18 \mathrm{~F}$. Minardi et al.

the needs of the present without compromising the ability of future generations to meet their own needs" (Emamisaleh \& Rahmani, 2017). SD concept applied to operations is introduced by Elkington (Elkington, 1998 [Cross Reference]), whilst also conceptualized the Triple-Bottom Line (TBL) approach i.e., the Economic-Social-Environmental impacts that businesses should be accountable for (Tidy, Wang, \& Hall, 2016). In addition, for facing unsustainable trajectories of the existing business model, the Circular Economy principle is widely considered as a paradigm to achieve SD (Nosratabadi, et al., 2019). The Circular Economy concept underlines the issue of transforming products by applying the $4 \mathrm{R}$ principles: reduce, recycle, reuse and recover at the individual company, industrial park and regional level, thus reducing the need for new inputs into production system (Genovese, Acquaye, Figueroa, \& Koh, 2017), (Pohlmann, Alves, Scavarda, \& Korzenowski, 2020). As a matter of fact, Circular Economy is "expected to promote economic growth by creating new businesses and job opportunities, saving materials' cost, dampening price volatility, improving security of supply while at the same time reducing environmental pressures and social impacts" (Kalmykova, 2018 [Cross Reference]) thereby addressing all the three dimensions of the TBL.

In general terms, a supply chain (SC) is designed to meet consumers' demands as efficiently and profitability as possible. The efficiency of planning, manufacturing and distributing a product in a network determines the success of a company (Lee \& Misni, 2015). Aiming at achieving the sustainability goal, different terms used to describe several types of SC can be identified: sustainable, closed-loop, lean [12] and short SC. The alignment of supply chain management (SCM) to the three issues of the TBL makes up the core concepts of Sustainable Supply Chain Management (SSCM) (ChardineBaumann \& Botta-Genoulaz, 2014 [Cross Reference]). A Closed-Loop SC describes both forward distribution operations and reverse flows. The forward SC includes the activities of procurement, design, manufacturing and distribution to consumer. On the contrary, reverse SC is related to the handling, storage, and transport of reusable products, components, waste or packaging (Manzini \& Accorsi, 2012). Therefore, a ClosedLoop SC is referred to as 'product-recovery management' (Sgarbossa \& Russo, 2017 ) or 'reverse SCM' (Genovese, Acquaye, Figueroa, \& Koh, 2017), a concept closed to circular industry. Besides, adopting Lean paradigm in SCM helps to focus on waste reduction that are processes or resources that have no value added for the end consumers, enhancing the importance of the workforce commitment (Krishnan, Agarwal, Bajada, \& Arshinder, 2020). Nowadays, a continuous increase of consumers' demand on safety, product diversity, local, organic and seasonal food, higher packaging and quality of services determines the adoption of shortest ways of delivering food, directly from producers to final consumers (Baez, Sequeira, \& Hilletofth, 2020). A Short FSC is defined as "a limited number of economic operators, committed to co-operation, local economic development, and close geographical and social relations between producers, processors and consumers" (European Parliament. Regulation (EU) No 1305/2013 of the European Parliament and of the Council of 17 December 2013 on Support for Rural Development by the European Agricultural Fund for Rural Development (EAFRD) and Repealing Council Regulation (EC), 2013 [Cross Reference]). Short Food Supply chains are identified as an economic opportunity for agriculture, as well as a driver for a more sustainable farming system (Filippini, Maraccini, Lardon, \& Bonari, 2016). 
The increasing attention paid to SD and SSCM concepts and the most recent scientific papers allow to figure out the well-known or best practices that companies should pursue to "green" their operations. However, studies across these topics frequently fail in taking into consideration the whole FSC. A best practice is defined as: "Any practice or experience which has proved its value or which is used in an efficient way in an organization, and can be applied in other organizations" . A best practice has three characteristics: it is formalized, reusable and effective (Chardine-Baumann \& BottaGenoulaz, 2014 [Cross Reference]). The third criteria include the relevance, coherence, effectiveness, efficiency, robustness and sustainability of the value created by the implementation of a practice.

This literature review allows to identify current trends and recent developments in this specific research direction. After a description of the research methodology, in Section 2, the analysis of the literature review is presented in Section 3. Section 4 provides the major SSCM practices. Finally, conclusions and future research directions are proposed in Section 5.

\section{Research Methodology}

The systematic literature review methodology is adopted as it is an approach of making sense of large bodies of information in a systematic way in order to provide coherent and robust evidence to address some compelling issues (Halim-Lim, et al., 2020). In this research, the main objective is to identify the present status of the literature in the area of SSCM in the food industry, in order to assess which are the practices that a company should implement in order to achieve the SD goal. To this end, the terms "Sustainable AND Supply AND Chain AND Management" and "Food AND Supply AND Chain" are applied to the titles, abstracts and keywords of research journal articles or review articles to sample the open access documents published in Scopus and ScienceDirect databases as they are internationally recognized and relevant scientific databases. Some filters are adopted by considering the subject are of the documents, such as "chemical engineering", "immunology", "biology", "veterinary", "neuroscience", "nursing". This allows to exclude not relevant contributions. Finally, a total of 324 relevant articles are identified (11 are found in the two databases at issue). Abstracts and conclusions of the selected papers are then read and analyzed. The documents dealing with Food-Energy-Water nexus, food rescue, Hotel, Restaurant and Catering SC are out of the boundaries of SSCM practices field and so not examined further. For the same reasons, some papers are excluded after the analysis of the full text. In the end, the selected articles cover two main topics: sustainable food SCM and the role of Information and Communication Technology in the food industry. This made up the initial corpus of papers. Furthermore, a forward and backward snowballing procedure have been carried out to ensure that all valuable knowledge has been identified (Wohlin, 2014) also from the studies not identified through the initial search process

\footnotetext{
${ }^{1}$ American Productivity and Quality Council (APQC). Available on http:// www.apqc.org.
} 
20 F. Minardi et al.

(Gunasekaran, Gawankar, \& Kamble, 2020). In the end, 224 articles are considered relevant for the further analysis.

\section{$3 \quad$ Results and Discussion}

By considering the year-wise distribution of the papers, this topic appears to be little discussed in the literature from 2008 (first year found through the query) to 2010 (2 out of 224). Then, the papers fluctuate slightly from 2012 to 2014 (22 out of 224). Another change of emphasis in research can be observed from 2015 to 2017 (62 out of 224). More recently, there is a considerable increase of research related to this topic (138 papers published between 2018 and 2020). This points out that the sustainability in the food industry is a recent field of study and that the general interests on this subject might be expected to increase in the future. Moreover, it is worth noticing that papers included after the forward analysis are twice with respect to the backward one. One of the most influential factors requiring food industries to move towards a more sustainable future is represented by the "2030 Agenda" dealing with the Sustainable Development Goals, agreed in 2015 by the United Nations General Assembly.

Most of the reviewed papers are coming from leading international journals such as Sustainability, Journal of Cleaner Production and International Journal of Production Economics. The contribution of these three ones represents exactly $50 \%$ of the documents set, the remaining $50 \%$ is made up by 79 different journals with a frequency of less than 5 articles per journal. Therefore, sustainability in the food industry is a granular and horizontal topic, discussed from the point of view of different journals.

The articles are classified in case-studies (43\%), empirical research (39\%) and literature reviews (18\%). Case-studies answer to both "why" and "how" questions in relation to a dynamic presented within the situation analyzed. Empirical research aims at answering empirical question through observation and documentation. Literature reviews are intended to evaluate and interpret the results obtained from previous academic findings. Six research methodologies are differentiated based on the way in which data are analyzed (cf. Fig. 1).

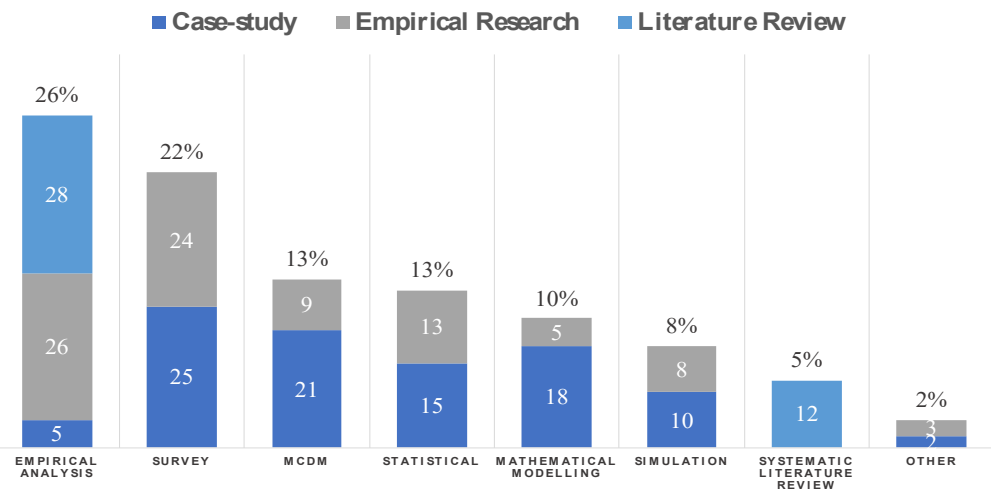

Fig. 1. Classification based on paper type and methodology. 
Most of the works are developed by analyzing a set of both primary and/or secondary data that according to (Joop \& Boeije., 2005) are information that are collected for the specific research problem. These studies are grouped under the Empirical Analysis label. Surveys (semi-structured interviews, direct or online interviews, field observation, workshops or surveys itself) are mostly carried out to evaluate the level of satisfaction of several individuals (Ex-post survey). In fact, only the $14 \%$ of these are intended to appraise the potential interest concerning the selected topic (Ex-ante survey). Statistical analyses are generally conducted to test hypotheses and uncover trends. Conversely, simulations are performed to optimize a given situation. With the intent to assess and predict possible outcomes, these are mostly adopted in Ex-ante evaluation. Multicriteria decision making analysis is a widespread methodology that deals with the economic, environmental and social impacts i.e., the three recognized dimensions of sustainability, that are perceived in the food chain. The multicriteria decision making methodologies used are for example the life cycle thinking approach or the Analytical Hierarchy Problem technique. These ones are intended to capture the real time situation and support decision makers by providing alternative strategies. Even if the life cycle thinking seems to be widely applied, the adoption of this approach to deal with sustainability issue is critically questioned in the literature. In the end, mathematical modelling includes Multi Integer Linear Programming or Multi Objectives Linear Programming problems, Inventory Routing Problems or it simply refers to mathematical models. When it comes to delivering general judgements on sustainability, models that rely only on quantitative data struggle with the quantification of intangible benefits that mostly compose the social aspect. Thus, some authors perform both qualitative and quantitative analysis. In fact, the approach of the reviewed studies is mainly qualitative (56\%) rather than quantitative $(34 \%)$ or both $(10 \%)$.

Since this literature review is intended to look at the SC operations, it is worth noticing in which part of the network the reviewed studies are focused on. The framework selected is the generic FSC model proposed by Gustavsson et al. (Gustavsson, Cederberg, \& Sonesson, 2011 [Cross Reference]). Moreover, the End-of-life stage is added to this model in order to count for papers that deal with the recycling, reuse, recovery and disposal of materials. With reference to the obtained results (cf. Fig. 2), papers generally consider more than one stage. It is worth noticing that 57 over 224 studies are not focused specifically on one or more stages of the SC. Agricultural production, that includes also breeding and fisheries activities, processing and distribution stages are equally addressed. So that, dealing with sustainability in the food industry, primary production activities have to be analyzed with the same importance as all the other more industry-related steps. Surprisingly, the end-of-life stage appears to be less addressed in the scholarly papers despite the importance of Circular Economy paradigm and the creation of Closed-Loop SC for achieving SD.

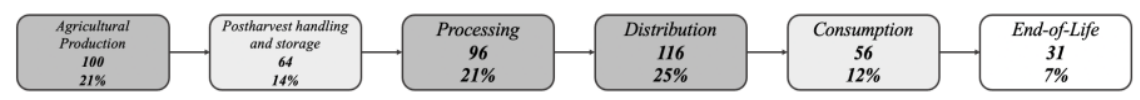

Fig. 2. Generic FSC model. 


\section{F. Minardi et al.}

This shows that even if the sustainability challenge of the food sector is increasingly studied, the research papers are mostly conducted for quantifying the impacts instead for finding solutions. In line with this, Ex-post works i.e., the analysis is performed by looking at the result of an event, account for $73 \%$ of the total while Ex-ante studies account for $27 \%$ of the total.

Articles vary in terms of geographical positioning: most of the articles are focused on European countries or developed nations in general. This is in line with the conclusions traced by Rehman Khan et al. [4] that emphasize the strong acceptability of sustainability ideas in developed nations, while developing countries are beginning to realize the importance and benefits of sustainable practices. The six leading European countries in terms of both number of authors and number of studies are the UK, Italy, Spain, France, The Netherlands and Germany. The same countries are the largest EU food and drink producers by turnover with reference to the 2020 report provided by the FoodDrink Europe organization (FoodDrink Europe, s.d.). Papers are focused more on unprocessed or minimally processed foodstuffs $(78 \%)$, rather than processed products $(17 \%)$ or culinary ingredients $(5 \%)$ according to the classification provided by Monteiro (Monteiro, 2012).

Finally, the integration of TBL axes is considered (cf. Fig. 3). As a result, while the economic and environmental aspects are generally included in the studies, the social aspect remains slightly less analyzed. Economically, cost remains the key factor. By considering the environmental dimension, the focus is on lowering the environmental burden that derives from human production and consumption. The social aspect refers to the development of the community and the image of the firm and their goods from the point of view of various stakeholders.

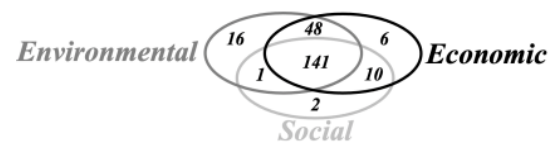

Fig. 3. TBL papers distribution.

\section{Overview of SSCM practices}

This section investigates the way a food company accomplishes the need to achieve SD i.e., the most common practices that can be implemented to reach this goal. A proper balancing between social responsibility, environmental preservation, economic prosperity and technological revolution plays the most prominent role (Pohlmann, Alves, Scavarda, \& Korzenowski, 2020), (Sgarbossa \& Russo, 2017 ). The model proposed by Zimon et al. (Zimon, Tyan, \& Sroufe, 2019) is used as a starting point to classify sustainable practices and it has been enlarged according to the findings of the literature review performed (cf. Fig. 4). In figure 4, the modifications are highlighted with *. The proposed framework is based on three main dimensions (upstream, focal company or downstream) while some other practices overlap with multiple dimensions (transverse). In addition, the waste management issue, introduced by Papargyropoulou et al. 
(Papargyropoulou, Lozano, Steinberger, Wright, \& Ujang, 2014) is considered. Prevention $(10.4 \%)$ and disposal $(1.0 \%)$ practices are investigated together with material and product recycling ( $\mathrm{P} 4)$ and product recovery and remanufacturing (P9). Prevention is the most desirable form of practices. On the contrary, disposal practices are the last ones that should be addressed. Percentages in brackets (cf. Fig. 4) refer to the relative attention the literature gives to each practice, by considering 1360 practices for a total of 224 papers. Differences from the original model are highlighted.

\subsection{Sustainable Supplier Management (Upstream)}

Sustainable Supplier Management, upstream the focal firm, includes sustainable sourcing and green purchasing. The former refers to suppliers' assessment (P1) and collaboration with suppliers (P2) (Mangla, et al., 2018), while green purchasing (P3), refers to consider environmental concerns along with other traditional factors in purchasing a product from the suppliers (Govindan, Kadziński, \& Sivakumar, 2016). The terms green purchasing and green procurement are used interchangeably (Luthra, et al., 2019). With reference to the attention paid to the practices included in this category from the point of view of both the number and the year-wise distribution of the works performed so far (cf. Appendix), it can be stated that these practices are well-established as their importance have been long discussed in literature as support in achieving SSCM.

\begin{tabular}{|c|c|c|c|}
\hline $\begin{array}{c}\text { Sustainable Supplier } \\
\text { Management } \\
\text { [upstream] } \\
\text { P1. Supplier Assessment }(9.6 \%) \\
\text { P2. Supplier Collaboration* }(1.9 \%) \\
\text { P3. Green Purchasing* }(4.9 \%) \\
\text { P4. Material and } \\
\text { Product Recycling }(2.4 \%)\end{array}$ & $\begin{array}{r}\text { Sustainable } \\
\text { Risk Ma } \\
\text { [Focal } \\
\\
\text { P5. Green D } \\
\text { P6. Green Pa } \\
\text { P7. Green Pro } \\
\text { P8. Green Man } \\
\text { P9. Product } \\
\text { Remanufac } \\
\text { P10. Integration } \\
\text { Management }\end{array}$ & $\begin{array}{l}\text { P7. Green Production* }(4.9 \%) \\
\text { P8. Green Manufacturing (4.6\%) } \\
\text { P9. Product Recovery and } \\
\text { Remanufacturing }(5.2 \%) \\
\text { P10. Integration of Environmental } \\
\text { Management Systems* }(7.4 \%)\end{array}$ & $\begin{array}{c}\text { Pressure \& Incentives } \\
\text { Management } \\
\text { [Downstream] }\end{array}$ \\
\hline \multicolumn{3}{|c|}{ Transversal Practices } & Collaborative practices $(9.0 \%)$ \\
\hline \multicolumn{2}{|c|}{$\begin{array}{l}\text { P16. Green Product Innovation and Design }(1.1 \%) \\
\text { P17. Corporate Social Responsibility programs }(9.6 \%) \\
\text { P18. Green Human Resource Management* }(1.9 \%) \\
\text { P19. Adoption of Standard and Certifications* }(5.1 \%)\end{array}$} & \multicolumn{2}{|c|}{$\begin{array}{l}\text { P20. Collaborative Supply Chain Planning } \\
\text { P21. Strategic Supply Collaboration } \\
\text { P22. Supply Chain Integration System }\end{array}$} \\
\hline
\end{tabular}

Fig. 4. Sustainable Supply Chain Management Practices, based on (Zimon, Tyan, \& Sroufe, 2019). 
24 F. Minardi et al.

\subsection{Sustainable Operations and Risk Management (Focal Company)}

From the focal company's point of view, the main practices implemented to achieve SD are green design $(\mathrm{P} 5)$, green packaging $(\mathrm{P} 6)$, green production $(\mathrm{P} 7)$, green manufacturing (P8) and integration of environmental management systems (P10). Their final aim is to reduce the environmental burden of products and/or processes, preserve the external environment and increase the operational efficiency of the company. The focus is on energy, water and soil conservation and management and animal welfare. All these green operations are supported by the deployment of green technologies (Boye \& Yves, 2013). Moreover, establishing key performance indicators helps to achieve a sustainable system (Makinde, Mowandia Tebogo, \& Michael, 2020), as well as the development of lean manufacturing solutions (Manzini \& Accorsi, 2012). In addition, the life cycle thinking approach is used in order to quantify the impacts on the three axes of sustainability and it helps to analyze where resources are used. It is worth noticing that green production and manufacturing practices have gained more attention in recent years with respect to the others.

\subsection{Pressure and Incentives Management (Downstream)}

Pressures and incentives, downstream the focal firm, include inventory management (P11), green warehouse (P12), green shipping and distribution ( $\mathrm{P} 13)$, reverse logistics (P14) and corporate green image management (P15). The first four practices can be conceptualized under the term eco- or green- logistics i.e., "plan the purchasing and consolidation of raw materials by the strategic and operative prospective, distribution towards final consumers/customers, reverse flow of packages due to post life treatments in agreement with shelf-life constraints, taking into consideration the impact on the environment in addition to the costs" (Manzini \& Accorsi, 2012). P14 could lead to the creation of Closed-Loop SC (Accorsi, Pini, Manzini, \& Baruffaldi, 2019). Nowadays, it is essential for firms to implement green practices in their operations to sustain the competition in the market. The deployment of green activities of a firm from the point of view of various stakeholders makes up the concept of green image (Luthra, et al., 2019).

\subsection{Transversal Practices}

Practices involving the entire SC consist of green product innovation and design (P16) i.e., any activities that results in new ideas or improvement addressing some specific sustainability targets (Nemecek, Kulak, Frossard, \& Gaillard, 2016), Corporate Social Responsibility programs ( $\mathrm{P} 17)$, green human resource management $(\mathrm{P} 18)$, adoption of standard and certifications (P19), a set of three collaborative practices (P20-P22) and the exploitation of information and communication technologies (P23).

By observing the yearly papers distribution, not surprisingly P17 appear to be one of the first discussed in the literature. Corporate Social Responsibility concept describes the set of voluntary initiatives carried out by a company to address social or environmental challenges in their own operations or in neighboring communities (Wiese, 2013 
[Cross Reference]). In fact, an initial step toward achieving holistic sustainability objectives lies in a corporation's orientation toward SD. Furthermore, within a company, P18 seeks to spread green values within a company, and it is a mechanism that can be employed by a firm to enhance its sustainability commitment (Jaaron, Zaid, \& Bon , 2018). In addition, a company specifies its engagement toward the SD by setting up standards (P19) which commonly comprise statements and policies to comply with legal requirements, by including also aspects that exceed regulatory concerns (Grimm, Hofstetter, \& Sarkis, 2016). Any party within the SC that does not comply with them might jeopardize the image of a firm. P19 is a key point across the whole SC as it is used as a demonstration that products or processes respect environmental and social criteria.

Collaboration is a common way for companies throughout the SC to share information, make strategic alliances, and reduce overall costs, also in terms of sustainability (Azevedo, Silva, Matias, \& Dias, 2018). In addition, collaboration is a practice historically adopted by farmers. The formalization of their collaboration is achieved by establishing agricultural cooperatives (Lutz, B., \& Grima, 2017). Thus, collaborative practices involve but it is not limited to collaborative supply chain planning (P20), strategic supply collaboration (P21) and supply chain integration system (P22).

Also, the adoption of Information and Communication Technologies (P23) has a significant impact on SSCM and appear to be a very recent field of study in the food industry. Economically, P23 allows to reduce costs and increase productivity. The positive impacts related to the environmental dimension can be ascribed to lower the consumption of resources, to reduce emissions and food losses and waste. Concerning the social aspect, P23 improves traceability, food safety, transparency, communication and coordination among actors (E1 Bilali \& Allahyari, 2018). Furthermore, the importance of e-commerce is often mentioned. Especially for Small and Medium Enterprises it might be an opportunity for supporting their business, reducing the cost and enhancing the demand (Kummer \& Milestad, 2020). In addition, it is recognized as one of best practices in gaining access to the market, also considering the restrictions due to COVID-19 pandemic (Mihailovic', et al., 2020).

\section{Conclusion and Future Research Directions}

The key objective of this research is to provide an overview of the recent developments in SSCM and related practices in the food industry via a systematic literature review. To date, the food industry industry has not yet been analyzed in depth compared to other sectors. In fact, the first study found through the queries is dated 2008. Moreover, during the pandemic, along with the drug industry, the food industry gained crucial importance worldwide. Thus, it deserves specific studies and analysis. Therefore, 224 relevant research papers are analyzed from Scopus and ScienceDirect databases. Based on the description of the theories underpinning the Sustainable Development concept, the findings reveal an increasing interest of research. The implications of this work are relevant for academics as they enlarge the body of knowledge on the adoption of sus- 
26 F. Minardi et al.

tainability practice in the food industry. From a practical point of view this study proposes an overview of the most common and adopted practices that can be implemented in order to achieve Sustainable Development in the food industry. In this sense, this work might be used as a framework for companies that are willing to assess their level of sustainability practices implementation. It provides a novel SCM practices model obtained via a systematic literature review as a precise approach methodology able to identify the most important research trends. This paper it is also a first attempt to assess the best practices that companies might implement to be aligned with the sustainability requirements. The framework can be compared with the industrial world as a preliminary standard by considering operational perspectives implications.

\section{References}

1. Rohmer, S. U. K., Gerdessen, J. C., Claassen, G. D. H.: Sustainable supply chain design in the food system with dietary considerations: A multi-objective analysis. European Journal of Operational Research, 273, 1149-1164 (2019).

2. Manzini, R., Accorsi, R.: The new conceptual framework for food supply chain assessment. Journal of Food Engineering, 115, 251-263 (2013).

3. Nosratabadi, S., Mosavi, A., Shamshirband, S., Zavadskas, E. K., Rakotonirainy, A., Chau, K. W.: Sustainable Business Models: A Review. Sustainability, 11(1663), (2019).

4. Rehman Khan, S. A., Yu, Z., Golpira, H., Sharif, A., Mardani, A.: A state-of-the-art review and meta-analysis on sustainable supply chain management: Future research directions. Journal of Cleaner Production, 278, (2021).

5. Emamisaleh, K., Rahmani, K.: Sustainable supply chain in food industries: Drivers and strategic sustainability orientation. Cogent Business \& Management, 4(1), (2017).

6. Elkington, J.: Partnerships from cannibals with forks: the triple bottom line of 21 st-century business. Environmental Quality Management, 8(1), 37-51 (1998) [Cross Reference].

7. Tidy M., Wang X., Hall, M.: The role of Supplier Relationship Management in reducing greenhouse gas emissions from food supply chains: supplier engagement in the UK supermarket sector. Journal of Cleaner Production 112, 3294-3305 (2016).

8. Genovese, A., Acquaye, A. A., Figueroa, A., Koh, S. L.: Sustainable supply chain management and the transition towards a circular economy: Evidence and some application. Omega 66, 344-357 (2017).

9. Pohlmann, C. R., Alves, M. B., Scavarda, A. J., Korzenowski, A. L.: The role of the focal company in sustainable development goals: A Brazilian food poultry supply chain case study. Journal of Cleaner Production, 245, (2020).

10. Kalmykova, Y.: Circular economy e from review of theories and practices to development of implementation tools. Resources, Conservation and Recycling, 135, 190-201 (2018) [Cross Reference].

11. Lee, L.S., Misni, F.: A Review on Strategic, Tactical and Operational Decision Planning in Reverse Logistics of Green Supply Chain Network Design. Journal of Computer and Communications, 5, 83-104 (2015).

12. Chardine-Baumann, E., Botta-Genoulaz, V.: A framework for sustainable performance assessment of supply chain management practices. Computers \& Industrial Engineering, 76, 138-147 (2014).

13. Sgarbossa, F., Russo, I: A proactive model in sustainable food supply chain: Insight from a case study. International Journal Production Economics, 183, 596-606 (2017).

14. Krishnan, R., Agarwal, R., Bajada, C., Arshinder, K.: Redesigning a food supply chain for environmental sustainability: an analysis of resource use and recovery. Journal of Cleaner Production, 242, (2020). 
15. European Parliament. Regulation (EU) No 1305/2013 of the European Parliament and of the Council of 17 December 2013 on Support for Rural Development by the European Agricultural Fund for Rural Development (EAFRD) and Repealing Council Regulation (EC), No 1698/2005; European Parliament: Brussels, Belgium, (2013) [Cross Reference].

16. Filippini, R., Maraccini, E., Lardon S., Bonari, E.: Is the choice of a farm's commercial market an indicator of agricultural intensity? Conventional and short food supply chains in periurban farming systems," Italian Journal of Agronomy, 11, (2016).

17. Baez, Y. P., Sequeira, M., Hilletofth, P.: Local and Organic Food Distribution Systems: Towards a Future Agenda. Operations and Supply Chain Management, 13, 336-348 (2020).

18. Halim-Lim, S. A., Chan, H. Y., Tan, T. B., Kamarulzaman, N. H., Jamaludin A. A., WanMohtar, W. A. A. Q. I.: Exploring the Drivers and the Interventions towards Sustainable Food Security in the Food Supply Chain. Sustainability, 12, (2020).

19. Wohlin, C.: Guidelines for snowballing in systematic literature studies and a replication in software engineering. In: 18th International Conference on Evaluation and Assessment in Software Engineering, pp. 1-10. EASE'14, London, England (2014).

20. Gunasekaran, A., Gawankar, S., Kamble, S.S.: Achieving sustainable performance in a datadriven agriculture supply chain: A review for research and applications. International Journal of Production Economics, 219, 179-194 (2020).

21. Joop, H. J., Boeije, H. R.: Data Collection, Primary vs Secondary. Enciclopedia of Social Management, 1, (2005).

22. Gustavsson, J., Cederberg, C., Sonesson, U.: Global food losses and food waste-Extent, Causes and Prevention. FAO: Rome, Italy (2011) [Cross Reference].

23. FoodDrink Europe, https:/www.fooddrinkeurope.eu/uploads/publications_documents/FoodDrinkEurope Data_Trends_2020_digital.pdf. Last accessed 13 January 2021.

24. Monteiro, C. A.: A new food classification based on the extent and purpose of industrial food processing. In: 8th International Conference on Diet and Activity Methods, FAO, Rome, (2012).

25. Zimon, D., Tyan, J., Sroufe, R.: Drivers of sustainable supply chain management: practices to alignment with UN sustainable development goals. International Journal for Quality Research, 14(1), 219-236 (2019).

26. Papargyropoulou, E., Lozano, R., Steinberger, J. K., Wright, N., Ujang, Z.: The food waste hierarchy as a framework for the management of food surplus and food waste. Journal of Cleaner Production, 76, 106-115(2014).

27. Mangla, S. K., Rich, N., Luthra, S., Kumar, D., Rana, N. P., Dwivedi, Y. K.: Enablers to implement sustainable initiatives in agri-food supply chains. International Journal of Production Economics, 203, 379-393 (2018).

28. Govindan, K., Kadziński, M., Sivakumar, R.: Application of a novel PROMETHEE-based method for construction of a group compromise ranking to prioritization of green suppliers in food supply chain. Omega, 71, 129-145 (2017).

29. Luthra, S., Raut, R. D., Narkhede, B. E., Mangla, S. K., Gardas, B. B., Priyadarshinee, P.: Examining the performance oriented indicators for implementing green management practices in the Indian agro sector. Journal of Cleaner Production, 215, 926-943 (2019).

30. Boye, J. I., Yves. A.: Current Trends in Green Technologies in Food Production and Processing. Food Engineering Reviews, 5, 1-17 (2013).

31. Makinde, O., Mowandia, M. T., Michael, A.: Performance evaluation of the supply chain system of a food product manufacturing system using a questionnaire-based approach. Procedia Manufacturing, 43, 751-757 (2020).

32. Accorsi, R., Pini, C., Manzini, R., Baruffaldi, G.: Environmental Impacts of Reusable Transport Items: A Case Study of Pallet Pooling in a Retailer Supply Chain. Sustainability, 11(3147), (2019). 
28 F. Minardi et al.

33. Nemecek, T., Kulak, M., Frossard, E., Gaillard, G.: Eco-efficiency improvement by using integrative design and life cycle assessment. The case study of alternative bread supply chains in France. Journal of Cleaner Production, 112, 2452-2461 (2016).

34. Wiese, W. and Toporowski, A.: CSR failures in food supply chains - an agency perspective. British Food Journal, 115(1), 92-107 (2013) [Cross Reference].

35. Jaaron, A. A., Zaid, A. A., Bon, A. T.: The impact of green human resource management and green supply chain management practices on sustainable performance: An empirical study. Journal of Cleaner Production, 204, 965-979 (2018).

36. Grimm, J.H., Hofstetter, J. S., Sarkis, J.: Exploring sub-suppliers' compliance with corporate sustainability standards. Journal of Cleaner Production, 112, 1971-1984 (2016).

37. Azevedo, S., Silva, E. M., Matias, C. O. J., Dias, G.: The influence of Collaboration Initiatives on the Sustainability of the Cashew Supply Chain. Sustainability, 10(2075), (2018).

38. Lutz, J., Smetschka, B., Grima, N.: Farmer Cooperation as a Means for Creating Local Food Systems-Potentials and Challenges. Sustainability, 9(925), (2017).

39. El Bilali, H., Allahyari, M. S.: Transition towards sustainability in agriculture and food systems: Role of information and communication technologies. Information Processing in Agriculture, 5, 456-464 (2018).

40. Kummer, S., Milestad, R.: The Diversity of Organic Box Schemes in Europe-An Exploratory Study in Four Countries. Sustainability, 12(2734), (2020).

41. Mihailović, B., Jean I. R., Popović, V., Radosavljević, K., Krasavac, B.C., BradićMartinović, A.: Farm Differentiation Strategies and Sustainable Regional Development. Sustainability, 12(7223), (2020). 


\section{Appendix}

$10,4 \%$

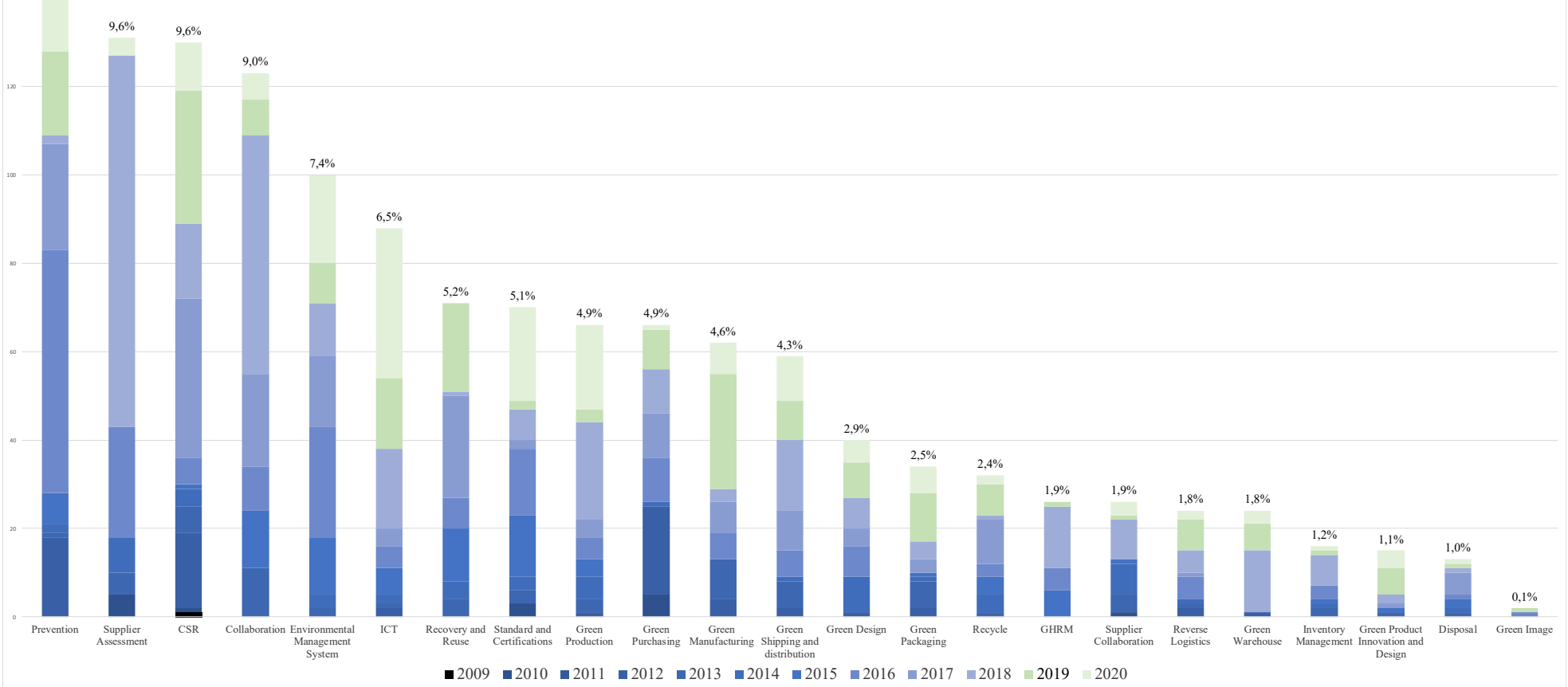

Fig. 5. Year-wise distribution of the practices with their relative importance 